\title{
BIBECHANA
}

A Multidisciplinary Journal of Science, Technology and Mathematics ISSN 2091-0762 (Print), 2382-5340 (0nline)

Journal homepage: http://nepjol.info/index.php/BIBECHANA

Publisher: Research Council of Science and Technology, Biratnagar, Nepal

\section{Factors intended to brain drain among nurses working at private hospitals of Biratnagar, Nepal}

\author{
Mamata Kadel ${ }^{1}$, Menuka Bhandari ${ }^{2 *}$ \\ ${ }^{1}$ Department of Nursing, Neuro Health College, Biratnagar, Nepal \\ ${ }^{2}$ Department of Child Health Nursing, Nursing Campus, Biratnagar, Nepal \\ "E-mail: menukamenu@gmail.com \\ Article history: Received 12 August 2018; Accepted 6 November, 2018 \\ http://dx.doi.org/10.3126/bibechana.v16i0.21642 \\ This work is licensed under the Creative Commons CC BY-NC License. \\ https://creativecommons.org/licenses/by-nc/4.0/
}

\section{(i) (9)}

Abstract

Introduction:The migration of health worker is a complex and multifaceted phenomena. Emigration of highly skilled and competent nurses to other countries seems to have negative impact on the delivery of excellent health care services.

Objective:The objective of this study was to assess factors intend to brain drain among nurses working at private hospitals of Biratnagar.

Methodology: A cross sectional study was conducted on staff nurses of selected hospitals of Biratnagar, Nepal from 2017 February to 2018 February; non-probability purposive sampling technique was used. Required information was collected using self-administered semi structured questionnaire related to demographic and factors intending to brain drain from 99 nurses.

Results: Majority (78.8\%) of nurses were below 25 years of age. Most (81.8\%) of them had completed PCL nursing, more than half (55.6\%) wanted to migrate abroad to pursue further work and study. Australia (56.4\%) and USA (25.5\%) emerged as the top destination of choice, while only (5.5\%) of them wanted to migrate United Kingdom. Lack of career opportunities, low salary and poor working condition were main pull factors and push factors intending to brain drain among nurses. This study also found that majority (96\%) of nurses were not satisfied with their salary.

Conclusion:More than half of nurses working in private hospitals would like to migrate abroad. The major push factors for migration was lack of career development and low salary.

Keywords:Brain drain; Private hospitals; pull factors and push factors.

\section{Introduction}

The term brain drain was first coined by the British Royal Society to refer to the exodus of scientists and technologists from the United Kingdom and Canada in the 1950s and 1960s to the United States. It is regarded as the international transfer of resources in the form of human capital and mainly applies to the migration of relatively highly educated individuals from developing to develop countries [1]. 
Throughout the 20th century, there have been a substantial number of highly skilled and educated professionals emigrating from their home countries in search of better economic and social opportunities in other countries. In the 1960s the term "brain drain" was coined in response to the large number of trained scientists, physicians and university teachers leaving developing countries [2].Migration of health workers 'Brain drain' is defined as the movement of health personnel in search of the better standard of living and life quality, higher salaries, access to advanced technology and more stable political conditions in different places worldwide. The migration of highly skilled workers from less-developed nations to industrialized nations is an inevitable part of the process of globalization and has positive and negative aspects. Trained health professionals are needed in every part of the world. However, better standards of living and quality of life, higher salaries, access to advanced technology and more stable political conditions in the developed countries attract talent from less developed areas. The majority of migration is from developing to developed countries. This is of growing concern worldwide because of its impact on the health systems in developing countries [3].An increasing number of nurses trained in Nepal, growing number of colleges with nurses at private sector have a strong desire to migrate, study and work abroad. Twenty years ago few nurse in Nepal had global aspiration and plan to migrate and settle in the west. This has completely changed. At present, new generation of nurses in Nepal are choosing nursing as a vehicle to migrate to the west and fulfill their modern aspiration [4].The large proportion of Nepal's health workforce is in the health management and support workforce that comprise of $38 \%$. The Nursing council estimates registering over 4000 new nurses in 2013. Yet, shortage of nurse persists in the public sector, district hospitals and primary health care center (PHC) is particular. There is mismatch between numbers of nursing professionals working in Nepal and annual registration of nursing professionals in Nepal Nursing Council (NNC).Study suggest a significant numbers of nursing professionals are working outside the country and non- health sectors [5].There is an abundance of Human Resources for Health (HRH) production, especially doctors and nurses, in Nepal but when it comes about employing they are underpaid and had to work laboriously often involving with harmful practices without compensation that demotivates them. Unlike other developing countries, "brain drain" of health workers has been identified as a major health concern in Nepal. Previous research has identified that professional councils are being approached for letters of good standing by staff wanting to work abroad and data suggests approximately $16 \%$ of registered doctors are outside the country. The uneven distribution of health workers has been a major concern in the health sector and the deployment of health personnel to the rural and remote areas of the country is a challenge. Although, Nepal produces an adequate number of doctors and nurses there are still huge shortage of qualified nurse midwife [6].Similar study done in Nepal showed that $52.22 \%$ of respondent were not satisfied with their job in Nepal. It was found that beside provision of modern facilities, age and personal ambition were also a motivating factor for nursing personnel migration [7].Emigration of highly skilled and competent nurses to other countries seems to have negative impact on the delivery of excellent health care services. Brain drain of Nepalese nurses is increasing day by day and shortage of health workforce is the burning issue of Nepal health care system. Therefore, researcher aims to study different factors intended to brain drain among the nurses of selected private hospitals of Biratnagar, Nepal.

\section{Methodology}

A cross-sectional study was conducted to identify the factors intended to brain drain among nurses of selected private hospitals of Biratnagar Metropolitan of Morang district. Biratnagar is the second largest city of Nepal, which consists of approximately 16 private registered hospitals. The study 
duration was 2017 February to 2018 February. Formal permission for the study was taken from the ethical committee of institute and written permission was obtained from selected hospitals. Informed consent was taken from the participants. Purposive sampling was used to select 99 registered nurses working in different private hospitals. Self-administered questionnaire was administered. Data was entered in Microsoft Excel and analyzed by statistical package for social sciences (SPSS). Mean, frequency, percentage and standard deviation was calculated.

\section{Results}

Table 1 shows the socio- demographic information of the study populations, in which mean age of participant was22.34 years with standard deviation of 2.94 years. Majority $(78.8 \%)$ of them were unmarried. Most of them (81.8\%) had completed PCL Nursing and 9.2\% had completed Bachelor level nursing respectively. More than half of the participants $(57.6 \%)$ immediate family members studied/worked/ permanently settled in abroad. According to table 2, most of the participants (96.96\%) were not satisfied with their salary while only (3.03\%) were satisfied.

Table 3 states that majority (39.4\%) of respondents want to pursue further study in abroad while only $(28.3 \%)$ of them planning to do further study in Nepal. Similarly respondent's intention to work in Nepal and abroad is equal (16.2\%). Among those who wanted to migrate abroad to pursue further study and work, Australia (56.4\%) and USA (25.5\%) emerged as the top destination of choice, while only $(5.5 \%)$ of them wanted to migrate to United Kingdom.

Table 4 indicates a multiple response question in which individuals were asked to rank each item. This table reveals those push and pull factors as ranked by participants as not important, less important and very important. The most important push factors were lack of career development (92.9\%), low salary $(90.9 \%)$ and poor working environment $(71.7 \%)$ and least important factors were political conflict (35.4\%) and family/friend influence (44.4\%). Similarly most important pull factors were better career development (87.9\%), high salary (86.9\%), better working environment $(81.8 \%)$ and better education $(77.8 \%)$ and least important pull factors were family/friend influence $(42.4 \%)$ and political stability (36.4\%).

Table 5 depicts respondents processing for migration, majority $76.8 \%$ have not precede any steps for migration while $6 \%$ have submitted college application, $8.1 \%$ have registered for country specific license examination and $9.1 \%$ have registered for language test.

Table 1: Socio-demographic characteristics of participants $(n=99)$.

\begin{tabular}{|l|c|c|}
\hline Variables & Frequency & Percentage \\
\hline Age in years & 78 & 78.8 \\
Below 25 & 21 & 21.2 \\
Above 25 & \multicolumn{2}{|c|}{$22.34 \pm 2.942$} \\
\hline Mean \pm SD & 38 & 38.6 \\
\hline Ethnicity & 24 & 24.2 \\
\hline Brahmin & 20 & 20.2 \\
Chettri & 3 & 3 \\
Madhesi & 7 & 7 \\
Muslim & 7 & 7 \\
Dalit & 21 & 21.2 \\
Janajati & 78 & 78.8 \\
\hline Marital status & \multicolumn{2}{|l}{} \\
\hline Married & \multicolumn{2}{|l|}{} \\
Unmarried & \multicolumn{2}{|c|}{} \\
\hline
\end{tabular}


Table 2: Participant's satisfaction with paid salary ( $\mathrm{n}=99)$.

\begin{tabular}{|l|c|c|}
\hline Response & Frequency & Percentage \\
\hline Satisfied & 3 & 3.03 \\
\hline Unsatisfied & 96 & 96.96 \\
\hline
\end{tabular}

Table 3: Distribution of participants according to future plan ( $n=99)$.

\begin{tabular}{|l|c|c|}
\hline Response & Frequency & Percentage \\
\hline Future plan & & \\
Further study in Nepal & 28 & 28.3 \\
Work in Nepal & 16 & 16.2 \\
Further study in abroad & 39 & 39.4 \\
Work in abroad & 16 & 16.2 \\
\hline Country selected for further & & \\
study/work & 31 & 56.4 \\
Australia & 14 & 25.5 \\
USA & 7 & 12.7 \\
Canada & 3 & 5.5 \\
UK & & \\
\hline
\end{tabular}

Table 4: Distribution of pull and push factors according to response ( $n=99)$.

\begin{tabular}{|c|c|c|c|}
\hline Factors & Not Important (\%) & Less Important(\%) & Very important $(\%)$ \\
\hline \multicolumn{4}{|l|}{ Push Factors } \\
\hline Lack of career development & 3 & 4 & 92.9 \\
\hline Low salary & 3 & 6.1 & 90.9 \\
\hline Poor working environment & 2.0 & 26.3 & 71.7 \\
\hline Unsatisfactory living condition & 11.1 & 38.4 & 50.5 \\
\hline Family/friends influence & 25.3 & 30.3 & 44.4 \\
\hline Poor quality of education & 15.2 & 31.3 & 53.5 \\
\hline Personal ambition & 15.2 & 25.3 & 59.6 \\
\hline Political conflict & 33.3 & 31.3 & 35.4 \\
\hline \multicolumn{4}{|l|}{ Pull Factors } \\
\hline Better career development & 6.1 & 5.1 & 87.9 \\
\hline High salary & 1.0 & 12.1 & 86.9 \\
\hline Better working environment & 5.1 & 13.1 & 81.8 \\
\hline Higher living standard & 7.1 & 28.3 & 64.6 \\
\hline Family/friends influence & 25.3 & 32.3 & 42.4 \\
\hline Better education & 11.1 & 11.1 & 77.8 \\
\hline Personal ambition & 17.2 & 19.2 & 63.6 \\
\hline Political stability & 32.3 & 31.3 & 36.4 \\
\hline
\end{tabular}

Table 5: Participant's processing for abroad $(\mathrm{n}=99)$.

\begin{tabular}{|l|c|c|}
\hline Response & Frequency & Percentage \\
\hline Submitted college application & 6 & 6 \\
Registered for country specific examination & 8 & 8.1 \\
Registered for language & 9 & 9.1 \\
Nothing done & 76 & 76.8 \\
\hline
\end{tabular}


The table 6 depicts respondent's response to consequences of brain drain. Majority $63.6 \%$ of respondents were known about consequences of brain drain. Multiple response questions was asked for consequences, $37 \%$ of respondents recognized shortage of skilled manpower as consequences, while $20 \%$ and $17 \%$ respondents recognized increased remittance and increased dependency in foreign technical assistance as consequences respectively. Majority, $81.8 \%$ of respondent's think that brain drain should be controlled.

Table 6: Distribution of participants according to consequences of brain drain $(\mathrm{n}=99)$.

\begin{tabular}{|l|c|c|}
\hline Response & Frequency & Percentage \\
\hline Known about consequences & 63 & 63.6 \\
Not known about consequences & 36 & 36.4 \\
Consequences & 37 & 37.4 \\
Shortage of skilled manpower & 20 & 20.2 \\
Increased remittance & 17 & 17.2 \\
Increased dependency in foreign technical assistance & & \\
Controlling brain drain & 81 & 18.2 \\
Yes & 18 & \\
No & & \\
\end{tabular}

Figure 1 reveals that $68.7 \%$ of respondents have planned to come back to Nepal once they are migrated.

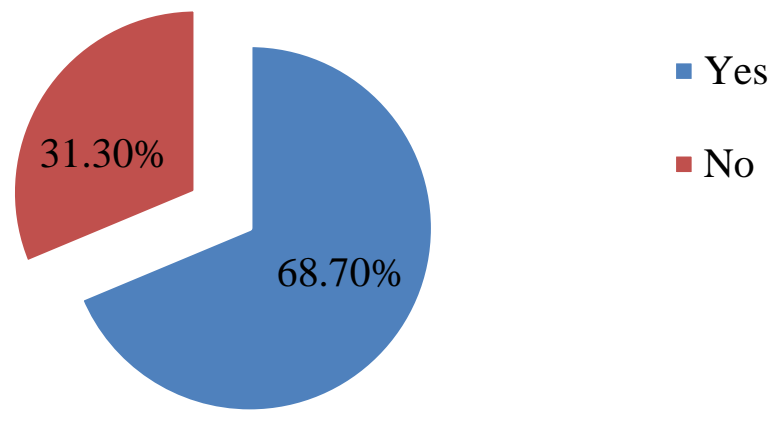

Fig. 1: Participants plan to come back to Nepal (n=99).

\section{Discussion}

This study revealed that majority (96\%) of respondents were not satisfied with their salary, whereas it compared by study conducted among migrated nurses from Nepal revealed that $55.22 \%$ of respondents were not satisfied with their salary and job in Nepal [7].In addition, research published by Connel states that the economic factors and the better working environment with more technological facilities in foreign countries are the main pulling factors of migration among doctors and nurses which is lacking in Nepal [8].This study found most of the (55.6\%) nurses wanted to 
migrate abroad to pursue study and work. Similar study conducted on "Factors driving nepali Health Workers to Seek Employment Opportunities in Abroad among Medical and Nursing students in Kathmandu" has shown that more than half of them planned to migrate abroad, to pursue further studies (39\%) and work (11.7\%) after completion of their degree program in Nepal [9].This study shows that most important push factors were lack of career development (92.9\%), low salary (90.9\%) and poor working environment $(71.7 \%)$ and least important push factors were political conflict (35.4\%) and family/friends influence (44.4\%). Similarly, most important pull factors were better career development (87.9\%), high salary (86.9\%), better working environment (87.8\%) and better education (77.8\%) and least important pull factors were family/friends influence (42.4\%) and political stability (36.4\%), whereas it is further supported by a study conducted on Health Workers Migration to UK, showed major push factors includes low pay condition, political instability and poor workplace security and the pull factors include increasing access to global market, better pay opportunities, living standard[10] .The World Health Report summarized a number of reasons why health workers moved to richer countries are lack of promotion prospects, Poor management, heavy workload, lack of facilities, declining health service, inadequate living conditions and high levels of violence and crime. These factors are closely related to Nepalese situation [11].According to World Health Organization, the insufficient number of health workers in less developed countries leads to delays in providing care, the closure of services, a lack of services in remote areas, excessive workload, demoralization, burn out, an inability to meet health goals and loss of life. These problems are further worsened by migration of health workers. Health workers, like workers in all sectors, tend to go where the working conditions are best. Income is an important motivation for migration, but not the only one. Other reasons include: greater job satisfaction, career opportunities, the quality of management and governance, moving away from political conflicts, war, and the threat of violence in the workplace [12].Majority $76 \%$ had not preceded any steps for migration while $6 \%$ had submitted college application, $8.1 \%$ had registered for country specific license examination and $9.1 \%$ had registered for language test. According to a study every year 250000 youth are reported to leave Nepal for higher living standards, employment, better income, education, a luring western lifestyle, stability and security, as our country seemed incapable to provide those to the youths. According to Nepal Nursing council records, a total number of 3461 nurses migrated abroad between 2002 and 2011. The number further increased to 4155 from 2011 to 2013 [13].Majority $63.6 \%$ of participants were known about consequences of brain drain. About $37 \%$ of respondents recognized shortage of skilled manpower as consequences, while $20 \%$ and $17 \%$ respondents recognized increased remittance and increased dependency in foreign technical assistance as consequences respectively. Majority, $81.8 \%$ of respondent's think that brain drain should be controlled. Many researches revealed that Young, well-educated, healthy individuals are most likely to migrate, especially in pursuit of higher education and economic improvement $[14,15]$. The distinction between 'push' and 'pull' factors has been recognized. Continuing disparities in working conditions between richer and poorer countries offer a greater 'pull' towards the more developed countries [16].

\section{Conclusion}

More than half of nurses working in private hospitals would like to migrate abroad. The major push factors for migration were lack of career development and low salary.

\section{Recommendations}

Career development opportunities, salary and working environment should be improved in Nepal which could be the strong and good motivating factors for Nepalese nurses to control them migrate 
abroad. The study can be replicated in large scale. A similar type of study can be conducted in different settings to increase representativeness of findings. Further research focused on various aspects of this complex phenomenon needs to be conducted to inform policies and programming dealing with it.

\section{Limitation of the Study}

This study was conducted only in private hospitals of Biratnagar. The findings were based on individual perception of the participants at private hospitals. The study could not cover all private hospitals of Biratnagar so the research findings would not be generalized.

\section{Acknowledgements}

The authors would like to acknowledge Tribhuvan University, Institute of Medicine, Biratnagar Nursing Campus for providing an opportunity to carry out this research. The researchers are ever indebted to the concerned private hospitals for permission and all nurses who consented and cooperated for study.

\section{Conflict of Interest}

The authors declare that no competing interest exists.

\section{Financial Disclosure}

No specific funding received for the study. Total expenditure was beard by authors themselves.

\section{References}

[1] A. Chimenya, B. Qi, Investigating determinants of brain drain of health care professionals in developing countries, Net Journal of Business Management 3(2) (2015)27-35.

[2] J. William, Carrington and Enrica Detragiache, "How Big Is the Brain Drain?" IMF Working Paper 98/102 (Washington), Finance and Development 36 (2) (1999).

[3] M.K. Bimal, R. Kaur, Factors intend to brain drain among staff nurse,Int. J. Adv. Nur. Management; 4(4) (2016) 327-330.DOI: 10.5958/2454-2652.2016.00073.

[4] R. Adhikari, The dream trap: Brokering, 'Study abroad' and nurse migration from Nepal to UK. European Bulletin of Himalayan Research30(3) (2009-2010) 122-138.

[5] MOHP \& NHSSP, Human Resource for Health: Nepal Country Profile, Kathmandu: Ministry of Health and Population,2014, Retrieved from http://www.searo.who.int/entity/human resources/data/hrh-profilenepal.

[6] J.B. Sherchand, Human Resources for Health (HRH) and challenges in Nepal, Journal of Institute of Medicine 35(2013) 1.

[7] R. Baral, S. Sapkota, Factors influencing migration among Nepalese nurses, Journal of Chitwan Medical College 5(12) (2015) 25-29.

[8] J. Connell, Migration of health workers in the Asia-Pacific region, Human Resources for Health Knowledge Hub, University of New South Wales, Sydney (2010) 1-28.

[9] B. Sijapati, J. Baniya, N. Choudhary, A. Bhtattarai, Migration of Health workers from Nepal, International Labour Organization, Retrieved from www.ceslam.org/index.php.

[10] T.N. Sapkota, E. Teijlingen, P. Simkhada, Nepalese health workers migration to UK. Health Science Journal, 8(1) (2104) 57-58.

[11] The World Health Report, Migration of Health Workers: WHO Code of Practice and The Global Economic Crisis, 2006.

[12] World Health Organization (WHO), Migration of health workers, fact sheet, July 2010, Available from: http://www. who.int/mesiacentre/factsheets/fs301/en/index.html

[13] S. Manandhar, Who pays the price for Nepal's Brain Drain? The Himalayan Times (Nepal), September 2010; 18:3. 
[14] A. Mejía, H. Pizurki, E. Royston, Physician and Nurse Migration: Analysis and Policy Implications. Geneva: World Health Organization, 1979.

[15] M. Awases, A.Gbary, J. Nyoni, R. Chatora, Migration of Health Professionals In Six Countries: Report. Brazzaville: WHO Regional Office For Africa, 2003.

[16] S. Bach, International Migration of Health Workers: Labour and Social Issues, Geneva: InternationalLabour Office, 2003 (www.ilo.org/public/english/dialogue/sector/papers/health/wp209.pdf). 